\title{
Body mass index has a curvilinear relationship with the percentage of body fat among children
}

\author{
Bruno Federico ${ }^{*}$, Filomena D'Aliesio, Fabio Pane, Giovanni Capelli and Angelo Rodio
}

\begin{abstract}
Background: Body Mass Index (BMI), which is defined as the ratio between weight (in $\mathrm{kg}$ ) and height (in $\mathrm{m}^{2}$ ), is often used in clinical practice as well as in large scale epidemiological studies to classify subjects as underweight, normal weight, overweight or obese. Although BMI does not directly measure the percentage of Body Fat (BF\%), it is widely applied because it is strongly related with $\mathrm{BF} \%$, it is easy to measure and it is an important predictor of mortality. Among children, age and sex-specific reference values of BMl, known as percentiles, are used. However, it is not clear how strong the relationship between $\mathrm{BMI}$ and $\mathrm{BF} \%$ is among children and whether the association is linear. We performed a cross-sectional study aiming at evaluating the strength and shape of the relationship between BMI and BF\% among school-aged children aged 6-12 years.

Findings: The study was conducted on a sample of 361 football-playing male children aged 6 to 12 years in Rome, Italy. Age, weight, height and skinfold thickness were collected. BF\% was estimated using 4 skinfold equations whereas BMI was converted into BMI-for-age z-score. The relationship between these variables was examined using linear regression analyses. Mean BMI was 18.2 ( \pm 2.8), whereas BF\% was influenced by the skinfold equation used, with mean values ranging from $15.6 \%$ to $23.0 \%$. A curvilinear relationship between BMl-for-age zscore and BF \% was found, with the regression line being convex. The association between BMl-for-age zscore and $\mathrm{BF} \%$ was stronger among overweight/obese children than among normal/underweight children. This curvilinear pattern was evident in all 4 skinfold equations used.
\end{abstract}

Conclusions: The association between BMI-for-age zscore and BF\% is not linear among male children aged 6-12 years and it is stronger among overweight and obese subjects than among normal and underweight subjects. In this age group, BMI is a valid index of adiposity only among overweight and obese subjects.

\section{Findings}

The percentage of Body Fat (BF\%) is currently estimated using several methods, which include underwater weighing, air displacement plethysmography, dual-energy Xray absorptiometry and bioelectrical impedance analysis [1]. Most of these methods are either extremely expensive or they require complex technologies and are therefore of limited use in clinical practice as well as in large scale epidemiological studies. Within these contexts, anthropometric methods may instead prove to be extremely useful [2]. Body Mass Index (BMI), defined as the ratio between body mass (in $\mathrm{kg}$ ) and height $\left(\right.$ in $\mathrm{m}^{2}$ ), is commonly used to define the conditions of obesity and overweight among adults [3]. Although BMI does not

\footnotetext{
* Correspondence: b.federico@unicas.it

Department of Health and Sport Sciences, University of Cassino, Cassino, Italy
}

(C) 2011 Federico et al; licensee BioMed Central Ltd. This is an open access article distributed under the terms of the Creative Commons Attribution License (http://creativecommons.org/licenses/by/2.0), which permits unrestricted use, distribution, and reproduction in any medium, provided the original work is properly cited. and it is very easy to measure. BMI is also an important predictor of mortality [4,5]. Among adults, BMI cut-off values of 25 and 30 define the conditions of overweight and obesity, respectively, whereas among children age and gender specific reference values of BMI, known as percentiles, are used [6]. Previous studies found that BMI was correlated with BF\% among children, too $[7,8]$. However, all these studies assumed the existence of a linear association between these two variables. In this study, we aimed at evaluating the strength and shape of the relationship between BMI and BF\% among schoolaged children.

Using a cross-sectional design, we examined a sample of 361 football-playing male children aged 6 to 12 years enrolled in the child division of Lazio football team in Rome, Italy. The study protocol was approved by the

\section{Biomed Central}


Table 1 Descriptive statistics of the sample

\begin{tabular}{lrrr}
\hline & N & Mean & SD \\
\hline Height $(\mathbf{c m})$ & 359 & 139.1 & 10.1 \\
Weight $(\mathbf{K g})$ & 361 & 35.9 & 9.1 \\
Body mass index $\left(\mathbf{K g} / \mathbf{m}^{2}\right)$ & 359 & 18.2 & 2.8 \\
Skinfold thickness $(\mathbf{m m})$ & & & \\
Biceps & 359 & 7.4 & 3.9 \\
Triceps & 360 & 11.5 & 4.8 \\
Subscapular & 359 & 8.9 & 5.5 \\
Suprailiac & 359 & 8.4 & 5.8 \\
Calf & 354 & 8.4 & 4.4 \\
Percentage body fat & & & \\
Deurenberg equation & 357 & 17.9 & 5.2 \\
Dezenberg equation & 360 & 23.0 & 5.3 \\
Slaughter equation 1 & 354 & 15.6 & 6.4 \\
Slaughter equation 2 & 359 & 18.5 & 7.0 \\
\hline
\end{tabular}

ethical review board of the Lazio football team child division. Informed consent to the study was given by either of the parents. Data collection was carried out by ad-hoc trained sports medicine physicians and anthropometric measurements such as weight, height and skinfolds thickness were performed for each subject. Biceps, triceps, subscapular, supra-iliac and calf skinfolds were all measured with Harpenden skinfold calipers. Skinfold thickness measurement was performed three times on the not dominant limb by a single operator, and the mean value of the three measurements was used. Data were first registered on a paper form and then stored into an electronic format using the software Epidata Entry. Data entry was performed in duplicate to minimize entry errors.

We used 4 skinfold equations in order to estimate BF $\%$ of each subject [9]. These equations, developed by Deurenberg, Dezenberg and Slaughter, are based on demographic data (age and gender), weight and different skinfolds depending on the equation used. BMI data were transformed into BMI-for-age z-scores using the LMS method and the reference data available from the 2000 CDC Growth Reference in the US [10,11]. Linear regression analyses were performed to evaluate the relationship between BMI z-score (the independent variable) and $\mathrm{BF} \%$ (the dependent variable). Subjects were also
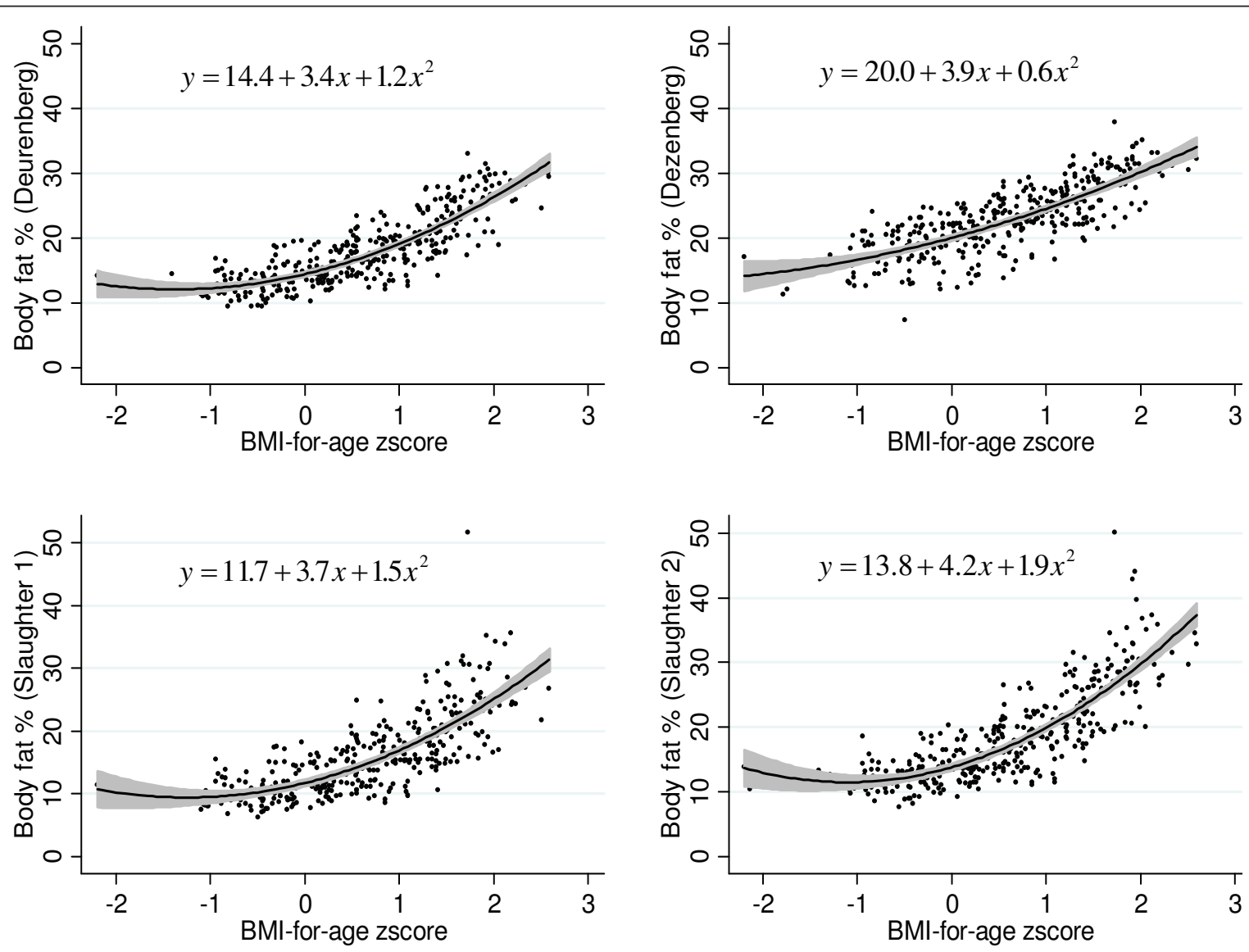

Figure 1 Scatterplot and regression line (with 95\% Confidence Intervals) of Body Fat percentage versus BMI-for-age zscore according to the four skinfold equations used. 
classified as overweight or obese according to the BMI cut-off points developed in an international survey [6]. All statistical analyses were carried out with Stata 11.2.

Sample descriptive statistics (mean and standard deviation) are shown in Table 1. Mean BMI was 18.2 ( \pm 2.8 ), whereas BF\% was influenced by the skinfold equation used, with mean values ranging from $15.6 \%$ using Slaughter 1 equation to $23.0 \%$ using Dezenberg equation. About 1 in 3 children was either overweight (24.4. $\%)$ or obese (5.6\%).

A curvilinear relationship between BMI-for-age zscore and $\mathrm{BF} \%$ was found, with the regression line being convex (Figure 1). This curvilinear pattern is evident in each of the 4 skinfold equations that we used to predict $\mathrm{BF} \%$. The addition of a quadratic term to the linear regression model significantly increased the proportion of the variability in BF\% explained by the model: in the case of Deurenberg equation (top left panel in Figure 1), $R^{2}$ increased from 0.66 to 0.72 . Values for $R^{2}$ for the quadratic model were 0.63 (Dezenberg), 0.60 (Slaughter 1 ), and 0.69 (Slaughter 2).

When the regression analysis was performed separately among normal and overweight/obese subjects, beta coefficients (which indicate the slope of the regression lines) were significantly smaller for the normal weight category than in the overweight/obese category. In the case of Deurenberg equation, beta coefficient was 2.9 among the former category, and 6.7 among the latter category $(p<0.001)$. Differences of a similar extent between beta coefficients were observed for the other 3 skinfold equations.

To conclude, our study shows that there is a curvilinear relationship between BMI-for-age z-score and BF $\%$, with strong correlations existing only among overweight and obese subjects. This finding is confirmed by the results of other studies, which used different methods of analyses [12-14], and it implies that the use of BMI as an index of adiposity among children is valid only among overweight and obese subjects.

List of abbreviations used

BMI: Body Mass Index; BF\%: Body Fat percentage

\section{Acknowledgements}

This study was partially funded by the Department of Health and Sport Sciences of the University of Cassino. We thank Dr. Saverio Tomaiuolo for revising the manuscript with regard to the use of the English language.

\section{Authors' contributions}

BF designed the study and drafted the manuscript. FDA and FP contributed to data collection and data analyses and they both contributed to revising the drafts. GC participated in the design of the study and performed data analyses. AR had the original idea of the study, he was responsible for data collection and he revised the drafts. All authors read and approved the final manuscript.

\section{Competing interests}

The authors declare that they have no competing interests.

Received: 26 May 2011 Accepted: 18 August 2011

Published: 18 August 2011

\section{References}

1. Sweeting HN: Measurement and definitions of obesity in childhood and adolescence: a field guide for the uninitiated. Nutr J 2007, 6:32.

2. Taylor RW, Keil D, Gold EJ, Williams SM, Goulding A: Body mass index, waist girth, and waist-to-hip ratio as indexes of total and regional adiposity in women: evaluation using receiver operating characteristic curves. Am J Clin Nutr 1998, 67:44-49.

3. Global Database on Body Mass Index. [http://apps.who.int/bmi/index.jsp]

4. Calle EE, Thun MJ, Petrelli JM, Rodriguez C, Heath CW Jr: Body-mass index and mortality in a prospective cohort of U.S. adults. N Engl J Med 1999, 341:1097-1105.

5. Wandell PE, Carlsson AC, Theobald H: The association between BMI value and long-term mortality. Int J Obes (Lond) 2009, 33:577-582.

6. Cole TJ, Bellizzi MC, Flegal KM, Dietz WH: Establishing a standard definition for child overweight and obesity worldwide: international survey. BMJ 2000, 320:1240-1243.

7. Maynard LM, Wisemandle W, Roche AF, Chumlea WC, Guo SS, Siervogel RM: Childhood body composition in relation to body mass index. Pediatrics 2001, 107:344-350.

8. Roche AF, Sievogel RM, Chumlea WC, Webb P: Grading body fatness from limited anthropometric data. Am J Clin Nutr 1981, 34:2831-2838.

9. Eisenmann JC, Heelan KA, Welk GJ: Assessing body composition among 3to 8-year-old children: anthropometry, BIA, and DXA. Obes Res 2004, 12:1633-1640.

10. Cole TJ: The LMS method for constructing normalized growth standards. Eur J Clin Nutr 1990, 44:45-60.

11. Kuczmarski RJ, Ogden CL, Guo SS, Grummer-Strawn LM, Flegal KM, Mei Z, Wei R, Curtin LR, Roche AF, Johnson CL: 2000 CDC Growth Charts for the United States: methods and development. Vital Health Stat 11 2002, 1-190.

12. Demerath EW, Schubert CM, Maynard LM, Sun SS, Chumlea WC, Pickoff A, Czerwinski SA, Towne B, Siervogel RM: Do changes in body mass index percentile reflect changes in body composition in children? Data from the Fels Longitudinal Study. Pediatrics 2006, 117:e487-495.

13. Lee K, Lee S, Kim SY, Kim SJ, Kim YJ: Percent body fat cutoff values for classifying overweight and obesity recommended by the International Obesity Task Force (IOTF) in Korean children. Asia Pac J Clin Nutr 2007, 16:649-655.

14. Schaefer F, Georgi M, Wuhl E, Scharer K: Body mass index and percentage fat mass in healthy German schoolchildren and adolescents. Int J Obes Relat Metab Disord 1998, 22:461-469.

doi:10.1186/1756-0500-4-301

Cite this article as: Federico et al:. Body mass index has a curvilinear relationship with the percentage of body fat among children. $B M C$ Research Notes 2011 4:301.

\section{Submit your next manuscript to BioMed Central and take full advantage of:}

- Convenient online submission

- Thorough peer review

- No space constraints or color figure charges

- Immediate publication on acceptance

- Inclusion in PubMed, CAS, Scopus and Google Scholar

- Research which is freely available for redistribution

Submit your manuscript at www.biomedcentral.com/submit
C BioMed Central 